Sains Malaysiana 47(8)(2018): 1625-1634

http://dx.doi.org/10.17576/jsm-2018-4708-01

\title{
Salvinia molesta dan Pistia stratiotes sebagai Agen Fitoremediasi dalam Rawatan Air Sisa Kumbahan
}

(Salvinia molesta and Pistia stratiotes as Phytoremediation Agents in Sewage Wastewater Treatment)

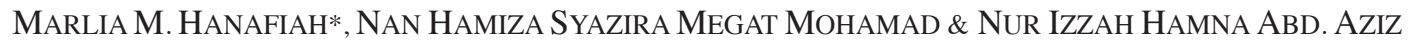

\begin{abstract}
ABSTRAK
Akumulasi logam berat dan bahan pencemar ke dalam ekosistem akuatik memberi impak negatif kepada alam sekitar dan organisma akuatik. Salvinia molesta dan Pistia stratiotes merupakan spesies yang mempunyai kadar pertumbuhan yang cepat dan berkemampuan dalam mengakumulasi logam berat dan menyerap nutrien menjadikan ia sesuai digunakan untuk merawat air sisa melalui kaedah bioteknologi iaitu fitoremediasi. Kajian ini dijalankan untuk menentukan kualiti air sisa kumbahan sebelum dan selepas rawatan menggunakan kaedah fitoremediasi. Selain itu, objektif kajian ini juga adalah untuk menilai keberkesanan Salvinia molesta dan Pistia stratiotes sebagai agen fitoremediasi bagi rawatan air sisa. Sampel tumbuhan akuatik berbeza berat iaitu 10, 20 dan $30 \mathrm{~g}$ diuji untuk rawatan tersebut. Ujian ANOVA satu hala menunjukkan perbezaan kadar pengurangan jumlah pepejal terampai dan ammoniakal nitrogen yang bererti $(\mathrm{p}<0.05)$ bagi 10, 20 dan $30 \mathrm{~g}$ Pistia stratiotes dan Salvinia molesta sepanjang kajian dijalankan iaitu daripada hari 0 sehingga hari ke-7. Keputusan kajian juga menunjukkan 30 dan $20 \mathrm{~g}$ Pistia stratiotes dan Salvinia molesta dapat menyingkirkan jumlah pepejal terampai dan ammoniakal nitrogen dengan lebih cepat berbanding berat tumbuhan $10 \mathrm{~g}$. Ujian ANOVA satu hala juga tidak menunjukkan perbezaan yang bererti bagi kadar pengurangan jumlah pepejal terampai dan ammoniakal nitrogen antara Pistia stratiotes dan Salvinia molesta.
\end{abstract}

Kata kunci: Air sisa kumbahan; fitoremediasi; Pistia stratiotes; Salvinia molesta

\section{ABSTRACT}

Accumulation of heavy metals and other pollutants into aquatic ecosystem has negative impacts on the environment and aquatic organisms. Salvinia molesta and Pistia stratiotes are both species that have a rapid growth rate and ability to accumulate heavy metals and absorb nutrients making these plants suitable to be used to treat wastewater through biotechnology method of phytoremediation. This study was conducted to determine the quality of sewage wastewater before and after treatment using phytoremediation. In addition, the objective of this study was to assess the effectiveness of Salvinia molesta and Pistia stratiotes as agents for the treatment of sewage wastewater. Samples with different aquatic plants with weight of 10,20 and $30 \mathrm{~g}$ were tested for the treatment. One-way ANOVA test showed a significant difference $(\mathrm{p}<0.05)$ in the rate of reduction of total suspended solids and ammoniacal nitrogen for 10,20 and $30 \mathrm{~g}$ of Pistia stratiotes and Salvinia molesta, from day 0 to day 7. The study also showed that the removal of total suspended solids and ammoniacal nitrogen using 30 and $20 \mathrm{~g}$ of Pistia stratiotes and Salvinia molesta were more efficient compared to $10 \mathrm{~g}$. One-way ANOVA test also showed no significant difference in the rate of reduction of total suspended solids and ammoniacal nitrogen between Pistia stratiotes and Salvinia molesta.

Keywords: Phytoremediation; Pistia stratiotes; Salvinia molesta; sewage wastewater

\section{PENGENALAN}

Air merupakan elemen penting untuk semua organisma hidup bermandirian dan menjalani kehidupan seharian. Namun begitu, pertambahan penduduk pada masa kini menyebabkan permintaan kepada bekalan air bersih semakin meningkat (Chavan \& Dhulap 2012). Air sisa hasil daripada aktiviti manusia seperti domestik, perindustrian, pertanian dan penternakan yang mengandungi bahan pencemar boleh memberi kesan kepada kesihatan manusia dan alam sekitar kerana mengandungi kandungan sebatian mineral bukan organik seperti sodium, potassium, kalsium, magnesium, kadmium, nikel dan zink (Bakar et al. 2016; Halim et al. 2017, 2015). Selain itu juga, air sisa kumbahan mempunyai kandungan pepejal terampai dan pepejal terlarut yang tinggi selain mengandungi kepekatan ammonia serta nitrogen dan fosforus yang kemungkinan terhasil daripada penguraian bahan organik di dalam air (Chavan \& Dhulap 2012). Air sisa yang tidak dirawat berisiko mendatangkan bahaya kepada manusia serta hidupan lain (Subramaniam et al. 2016; Warrier 2012).

Keperluan pengurusan dan rawatan air sisa adalah penting bagi menangani krisis kekurangan bekalan air bersih, isu pencemaran sumber air, kos rawatan air yang semakin meningkat serta peraturan pelepasan air sisa yang semakin ketat. Bagi mengatasi masalah ini, kaedah 
fitoremediasi merupakan salah satu alternatif dalam merawat air sisa dengan menyingkirkan logam berat serta memerangkap nutrien dan mikroorganisma berbahaya yang terhasil daripada aktiviti perindustrian mahupun domestik (Meagher 2000). Fitoremediasi merupakan satu kaedah rawatan yang menggunakan tumbuhan untuk tujuan degradasi, pengekstrakan atau penyingkiran bahan pencemar dalam tanah dan air (Suhaimi \& Samah 2013).

Kelebihan menggunakan kaedah fitoremediasi adalah rawatan ini mesra alam dan merupakan satu proses semula jadi yang tidak memerlukan bahan kimia sintetik serta kos aplikasi yang rendah. Rawatan fitoremediasi menggunakan tumbuhan akuatik berupaya daripada segi biologinya untuk menyerap logam berat dan nutrien yang terdapat dalam air sisa serta memperbaiki tahap kualiti air (Baharim et al. 2016; Dixit et al. 2011; Elias et al. 2014; Manan et al. 2015; Rahman \& Hasegawa 2011). Berdasarkan kajian lepas (Ng \& Chan 2016; Rahman \& Hasegawa 2011; Warrier 2012), terdapat beberapa jenis tumbuhan akuatik yang berpotensi sebagai agen fitoremediasi seperti Salvinia molesta, Pistia stratiotes, Azolla pinnata, Hydrilla verticillata, Pteris vittata, Rumex acetosa dan Sebertia acuminata.

Kajian ini dijalankan untuk menentukan kadar pengurangan jumlah pepejal terampai dan ammoniakal nitrogen di dalam air kumbahan melalui kaedah fitoremediasi dengan menilai kualiti air sisa kumbahan sebelum dan selepas rawatan dijalankan. Keberkesanan rawatan air sisa di antara dua tumbuhan yang berbeza (Salvinia molesta dan Pistia stratiotes) dibandingkan bagi berat tumbuhan yang berbeza $(10,20$ dan $30 \mathrm{~g})$. Tumbuhan akuatik seperti Salvinia molesta dan Pistia stratiotes dipilih dalam kajian ini kerana mempunyai kadar pertumbuhan yang cepat serta berdasarkan kajian lepas oleh $\mathrm{Ng}$ dan Chan (2016), Salvinia molesta dan Pistia stratiotes mampu mengurangkan kadar nutrien yang ada dalam buangan daripada kilang minyak kelapa sawit sebanyak $85 \%$. Sifat fizikal yang hampir sama pada Salvinia molesta dan Pistia stratiotes daripada segi jenis akar dan kedua-keduanya terapung pada permukaan badan air turut menjadi faktor pemilihan kedua-dua spesies tumbuhan ini. Selain itu juga, tumbuhan akuatik ini mempunyai kadar pertumbuhan yang sangat cepat sehingga mampu membentuk tikar pada permukaan air yang mampu mencapai tiga kaki kedalaman (Lemon \& Posluszny 1997).

\section{BAHAN DAN KAEDAH}

Kajian ini telah dijalankan dengan menggunakan sampel air sisa kumbahan yang diambil di tiga stesen Loji Kumbahan Kawasan Perumahan UKM, Bangi (Rajah 1). Air sisa kumbahan yang diperoleh dimasukkan ke dalam botol berisi padu $10 \mathrm{~L}$ dan disimpan di dalam bilik sejuk pada suhu $4^{\circ} \mathrm{C}$. Ujian di lapangan (in-situ) dan ujian di makmal (ex-situ) dijalankan untuk penentuan beberapa parameter fiziko-kimia seperti suhu, $\mathrm{pH}$, kekonduksian, oksigen terlarut (DO), jumlah pepejal terampai (TSS), ammoniakal nitrogen $\left(\mathrm{NH}_{3}^{-} \mathrm{N}\right)$, permintaan oksigen kimia (COD) dan permintaan oksigen biokimia (BOD) (Rajah 2). Analisis awal kualiti air dilakukan sebelum rawatan fitoremediasi. Selepas rawatan fitoremediasi, kadar pengurangan jumlah pepejal terampai (TSS) dan ammoniakal nitrogen $\left(\mathrm{NH}_{3}{ }_{3} \mathrm{~N}\right)$ ditentukan.

Tumbuhan yang dipilih adalah tumbuhan akuatik yang mempunyai kadar pertumbuhan yang cepat dan mempunyai struktur akar yang hampir sama. Kedua-dua tumbuhan ini iaitu Salvinia molesta (Rajah 3(a)) dan Pistia stratiotes (Rajah 3(b)) merupakan tumbuhan yang hidup dalam air yang bergerak perlahan atau bertakung seperti tasik dan kolam. Salvinia molesta dan Pistia stratiotes diperoleh dari Tasik Chini, Pahang dan kedai landskap. Sampel tumbuhan tersebut dibersihkan terlebih dahulu di bahagian akar untuk mengelakkan berlakunya pengumpulan bahan pencemar. Kedua-dua sampel dibiarkan di dalam bekas berisi air paip selama satu minggu untuk memastikan kestabilan serta meneutralkan keadaan tumbuhan tersebut.

Kedua-dua tumbuhan tersebut dibahagikan kepada 3 berat yang berbeza iaitu 10, 20 dan 30 g. Sebanyak 12 bekas disediakan iaitu 6 bekas diisikan dengan air sampel

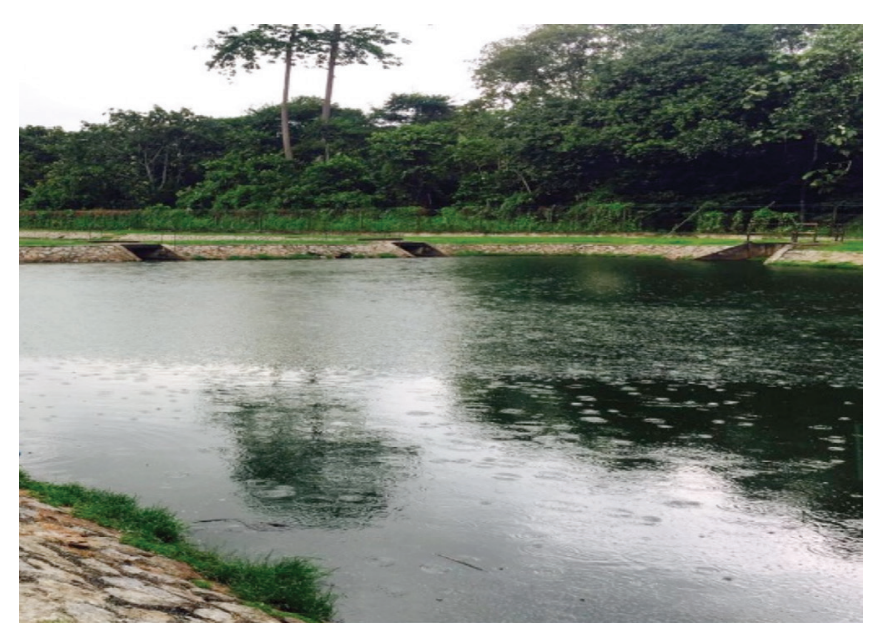

RAJAH 1. Loji kumbahan 


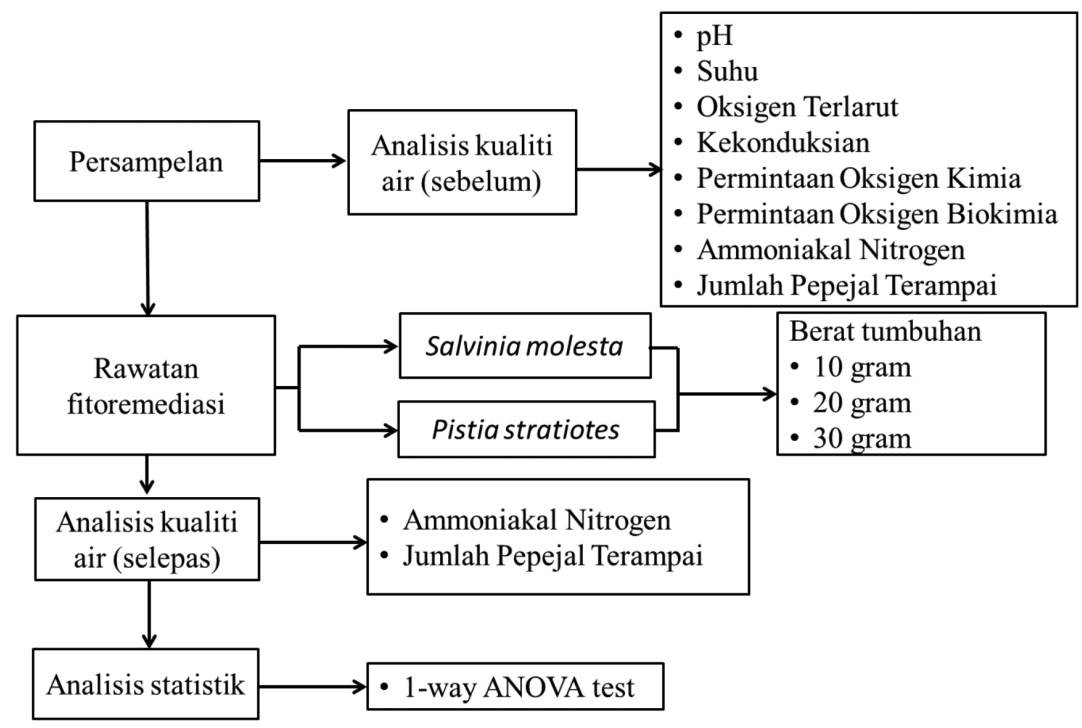

RAJAH 2. Carta alir kaedah kajian
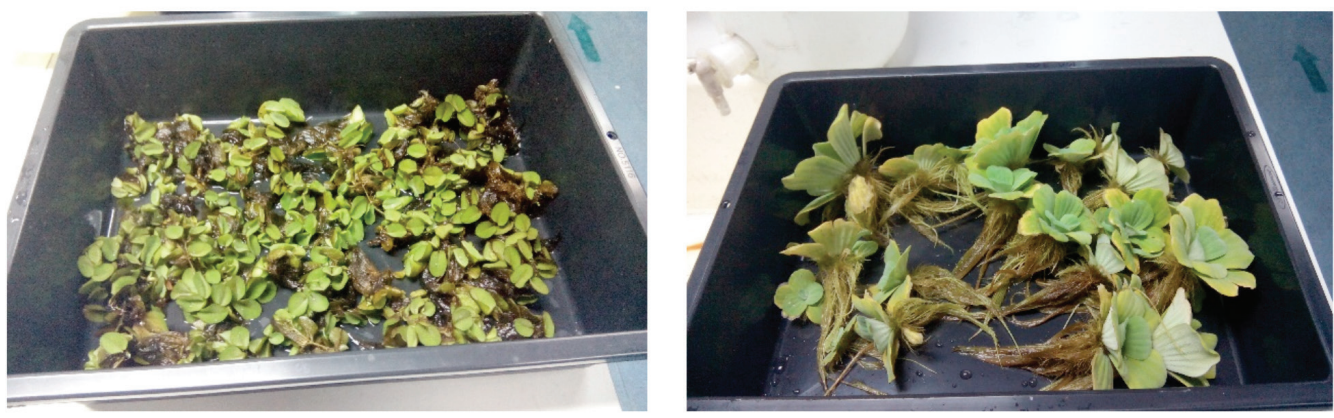

RAJAh 3. a) Salvinia molesta dan b) Pistia stratiotes

manakala 6 bekas lagi diisi dengan air paip sebagai kawalan (Jadual 1). Rajah 4 dan 5 masing-masing menunjukkan bekas rawatan sampel air kumbahan menggunakan Pistia stratiotes dan Salvinia molesta. Kajian ini dijalankan selama 8 hari. Sebanyak 3 replikasi dijalankan bagi analisis kadar pengurangan jumlah pepejal terampai (TSS) dan ammoniakal nitrogen $\left(\mathrm{NH}_{3}{ }^{-} \mathrm{N}\right)$. Bacaan kadar pengurangan direkodkan setiap hari daripada hari pertama hingga hari ke lapan.

Kawalan kualiti telah dilakukan dengan memastikan kesemua peralatan yang digunakan direndam di dalam larutan asid nitrik 5\% dan dibilas dengan air suling selama semalaman. Peralatan dikeringkan terlebih dahulu sebelum digunakan. Selain itu, peralatan lain seperti silinder penyukat dan bikar dibilas menggunakan air suling terlebih dahulu sebelum digunakan. Alat-alat yang digunakan telah dikalibrasi mengikut piawaian yang ditentukan sebelum digunakan.

\section{ANALISIS STATISTIK}

Data-data yang diperoleh dikumpul dan disusun dengan menggunakan perisian IBM SPSS Statistik versi 22. Ujian
ANOVA satu hala digunakan untuk melihat perbezaan jumlah pepejal terampai dan ammoniakal berbeza berat $(10,20,30 \mathrm{~g})$ daripada hari 0 sehingga hari terakhir rawatan. Ujian ANOVA juga digunakan untuk melihat perbandingan perubahan jumlah pepejal terampai dan ammoniakal nitrogen bagi Pistia stratiotes dan Salvinia molesta. Ujian Tukey juga digunakan untuk melihat perbezaan signifikan yang wujud bagi setiap varians parameter yang diuji.

\section{KEPUTUSAN KAJIAN DAN PERBINCANGAN}

\section{KUALITI AIR SEBELUM RAWATAN FITOREMEDIASI}

Bacaan bagi beberapa parameter kualiti air sebelum rawatan fitoremediasi ditunjukkan dalam Jadual 2. Nilai pH bagi sampel air kumbahan dalam kajian ini menunjukkan bacaan kelas III berdasarkan piawaian kualiti air kebangsaan (NWQS) iaitu antara 5-9. Nilai $\mathrm{pH}$ sampel ialah 5.71 menunjukkan air kumbahan tersebut berada dalam keadaan sedikit berasid. Hal ini disebabkan air yang terdapat dalam kolam kumbahan tersebut adalah 
JADUAL 1. Ilustrasi untuk penyediaan sampel air sisa dan tumbuhan

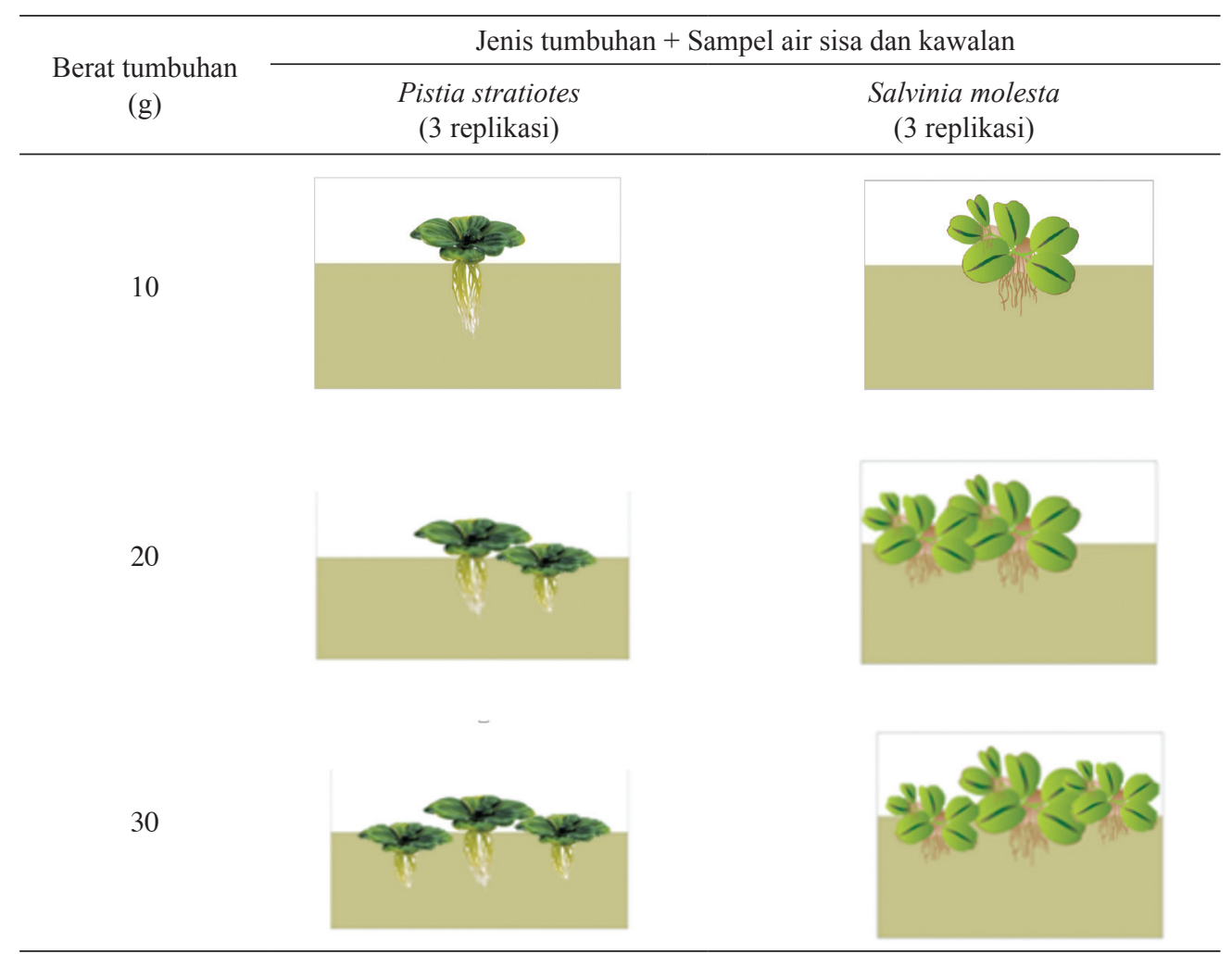

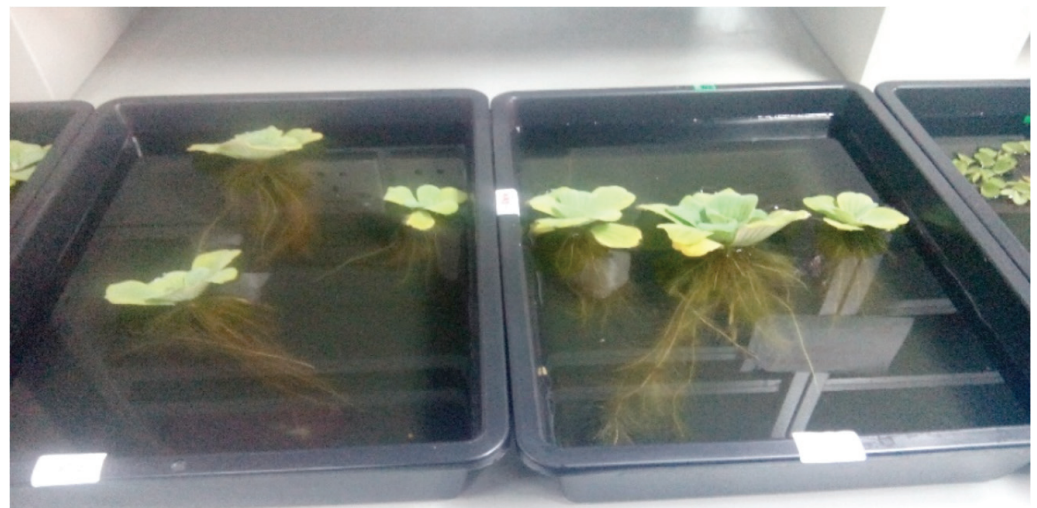

RAJAH 4. Rawatan sampel air kumbahan menggunakan Pistia stratiotes

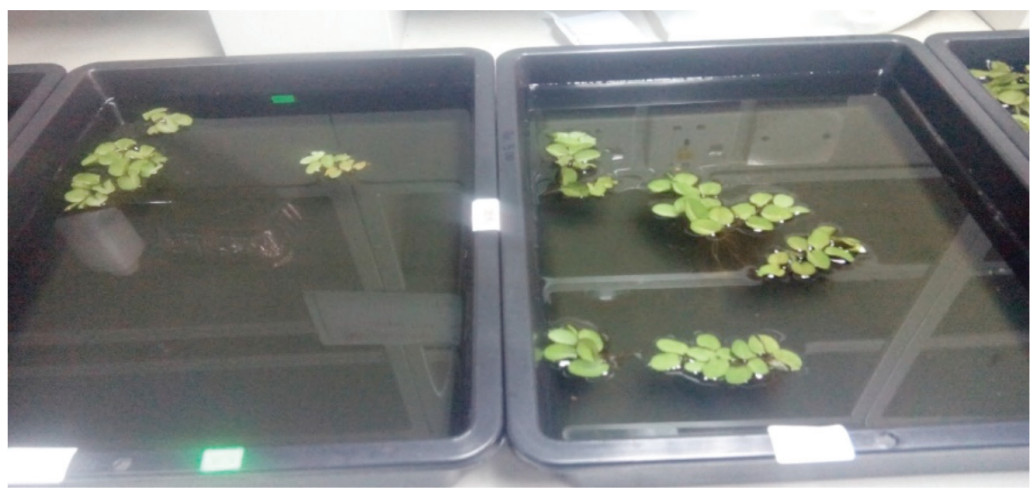

RAJAH 5. Rawatan sampel air kumbahan menggunakan Salvinia molesta 
JADUAL 2. Kualiti air sebelum rawatan fitoremediasi

\begin{tabular}{lccc}
\hline Parameter & Purata bacaan & Unit & Sisihan piawai \\
\hline $\mathrm{pH}$ & 5.71 & - & 0.009 \\
Jumlah pepejal terampai (TSS) & 31.54 & $\mathrm{mg} / \mathrm{L}$ & 14.83 \\
Oksigen terlarut (DO) & 6.77 & $\mathrm{mg} / \mathrm{L}$ & 0.07 \\
Permintaan oksigen biokimia (BOD) & 1.99 & $\mathrm{mg} / \mathrm{L}$ & 0.9 \\
Permintaan oksigen kimia (COD) & 116 & $\mathrm{mg} / \mathrm{L}$ & 25.2 \\
Ammoniakal nitrogen $\left(\mathrm{NH}_{3}-\mathrm{N}\right)$ & 1.7 & $\mathrm{mg} / \mathrm{L}$ & 0.67 \\
\hline
\end{tabular}

tangki takungan air sisa domestik yang berpunca daripada saluran perumahan di sekitar loji perumahan tersebut. Air sisa ini turut mengandungi air basuhan serta mandian daripada kawasan perumahan dan memberi kesan kepada $\mathrm{pH}$ air kumbahan tersebut.

Kandungan TSS iaitu $31.54 \mathrm{mg} / \mathrm{L}$, menunjukkan bacaan pada kelas II berdasarkan piawaian. Jumlah pepejal terampai (TSS) merupakan zarah bukan organik dalam air yang bersaiz lebih besar daripada $0.001 \mathrm{~mm}$. Menurut Azahan et al. (2001), TSS merupakan petunjuk pencemaran akibat daripada kegiatan pembangunan tanah, perlombongan dan hakisan selain disebabkan oleh berlakunya pertumbuhan alga. TSS meningkat pada hari hujan kerana air larian daripada hujan mempunyai daya hakisan yang kuat dan mengakibatkan kadar hakisan tanah yang kuat dan menyumbangkan kepada peningkatan pepejal terampai di kawasan tanah rata. Sampel air yang digunakan merupakan air sisa kumbahan yang mempunyai potensi untuk berlakunya pertumbuhan alga berserta kewujudan bahan-bahan yang tidak terlarut ketika proses rawatan awal air sisa kumbahan tersebut. Kandungan TSS juga dipengaruhi oleh lokasi persampelan bagi air kumbahan tersebut kerana sampel air kumbahan tersebut diperoleh dari kawasan pegun yang mempunyai pergerakan air yang perlahan. Ini meningkatkan lagi pertumbuhan alga di loji kumbahan tersebut seterusnya memberi kesan kepada kandungan TSS.

Purata bagi bacaan oksigen terlarut (DO) ialah 6.77 $\mathrm{mg} / \mathrm{L}$. Kuantiti oksigen terlarut bergantung kepada tekanan udara, suhu dan kandungan garam terlarut (Ma' arof \& Hua 2015). Pengurangan oksigen terlarut berlaku sekiranya kandungan bahan organik tinggi di dalam air (Din et al. 2012). Menurut Gasim et al. (2012), penggunaan oksigen yang tinggi oleh mikroorganisma menyumbang kepada pengurangan kandungan oksigen terlarut di dalam air. Kadar aliran air sisa daripada perumahan tersebut perlu dikawal bagi mengelakkan kekurangan kandungan oksigen terlarut dalam air kumbahan kerana akan mengganggu aktiviti mikroorganisma yang hadir di kawasan tersebut.

Nilai BOD pula berada di kelas II berdasarkan NWQS iaitu nilai kurang daripada $3 \mathrm{mg} / \mathrm{L}$. Permintaan oksigen biokimia (BOD) merupakan ukuran kuantiti oksigen yang diperlukan mikroorganisma untuk mengoksidakan bahan organik dalam keadaan berudara (Suratman et al. 2005). Ujian parameter BOD dijalankan untuk mengetahui kuantiti oksigen yang digunakan semasa tindak balas penguraian bahan organik yang berlaku secara semula jadi (Ma'arof \&
Hua 2015). Menurut Din et al. (2012), semakin tinggi nilai BOD di dalam jasad air, semakin tinggi tahap pencemaran air daripada segi kandungan organik dalam badan air tersebut. Selain itu, air sisa daripada saliran yang terdapat di sekitar loji kumbahan tersebut turut menyumbang kepada peningkatan dan kepekatan nilai BOD dalam jasad air. Ditambah pula dengan keadaan hujan yang kurang dan sistem kolam takungan yang digunakan bagi air kumbahan tersebut menyumbang kepada peningkatan aktiviti penguraian bahan organik oleh mikroorganisma.

Nilai COD pula berada pada kelas V berdasarkan NWQS iaitu melebihi 100 mg/L. Permintaan oksigen kimia (COD) merupakan jumlah oksigen yang diperlukan untuk mengoksidakan bahan kimia organik dan bukan organik yang terdapat dalam jasad air. Nilai COD meningkat apabila kepekatan bahan organik dalam jasad air meningkat (Gasim et al. 2012). Nilai purata bagi bacaan COD ialah $116 \mathrm{mg} / \mathrm{L}$, menunjukkan satu bacaan yang agak tinggi. Kenaikan nilai COD boleh dikaitkan dengan pembuangan sisa kimia ke dalam saluran kolam takungan air kumbahan seperti raksa daripada projek baik pulih jalan di kawasan berdekatan dengan longkang saliran. Selain itu juga, kadar turunan hujan juga memainkan peranan penting kepada kandungan COD di dalam jasad air. Menurut kajian oleh Din et al. (2012), kandungan COD ini amat dipengaruhi oleh keamatan hujan dan halaju arus. Semakin tinggi keamatan hujan yang diterima, semakin tinggi halaju arus menyebabkan semakin rendah beban pencemar COD dalam air. Sebaliknya, semakin kurang keamatan hujan, semakin perlahan halaju arus maka semakin tinggi kepekatan bahan pencemar ini.

Nilai bacaan ammoniakal nitrogen $\left(\mathrm{NH}_{3}{ }^{-} \mathrm{N}\right)$ yang diperoleh menunjukkan kelas IV iaitu kurang daripada $2.7 \mathrm{mg} / \mathrm{L}$. Ammonia adalah sebatian yang biasanya terdiri daripada proses degradasi bahan organik bernitrogen. Ammonia yang tidak terion adalah toksik kepada hidupan akuatik. Apabila larut di dalam air, $\mathrm{NH}_{3}$ akan bertindak balas dengan air untuk membentuk ion ammonia $\mathrm{NH}_{4}$ dengan bakinya kekal sebagai $\mathrm{NH}_{3}$. $\mathrm{NH}_{3}$ boleh dioksidakan kepada nitrit $\mathrm{NO}_{2}$ dan kemudiannya kepada nitrat $\mathrm{NO}_{3}$ oleh bakteria Nitrosomonas dan Nitrobacter. Proses pengoksidaan $\mathrm{NH}_{3}$ kepada $\mathrm{NO}_{3}$ pula menggunakan oksigen terlarut dalam kuantiti yang banyak. Kandungan $\mathrm{NH}_{3}$ dalam air diukur berdasarkan jumlah kepekatan ammonia. $\mathrm{NH}_{3}$ dalam kepekatan yang sedikit dan juga $\mathrm{NO}_{3}$ menjadi sumber penting kepada pertumbuhan alga (Shuger et al. 2001). Berdasarkan Jadual 2, nilai purata 
bagi bacaan $\mathrm{NH}_{3}{ }_{3} \mathrm{~N}$ di lokasi persampelan ialah $1.71 \mathrm{mg} / \mathrm{L}$. Bacaan $\mathrm{NH}_{3}{ }^{-} \mathrm{N}$ yang tinggi disebabkan oleh kandungan sisa buangan yang datang daripada perumahan yang disalurkan terus ke loji kumbahan tersebut.

PENGURANGAN KANDUNGAN AMMONIAKAL NITROGEN $\left(\mathrm{NH}_{3}{ }^{-} \mathrm{N}\right)$ DAN JUMLAH PEPEJAL TERAMPAI (TSS) DI DALAM AIR SISA KUMBAHAN AMMONIAKAL NITROGEN $\left(\mathrm{NH}_{3}^{-} \mathrm{N}\right)$

Rajah 6 menunjukkan kadar pengurangan $\mathrm{NH}_{3}{ }^{-} \mathrm{N}$ menggunakan $10 \mathrm{~g}$ tumbuhan fitoremediasi iaitu Pistia stratiotes dan Salvinia molesta. Nilai bacaan tertinggi bagi kedua-dua sampel air kumbahan menggunakan Pistia stratiotes dan Salvinia molesta masing-masing ialah 6.85 dan $8.1 \mathrm{mg} / \mathrm{L}$ pada hari pertama rawatan. Sampel air kumbahan yang diletakkan tumbuhan Salvinia molesta mengalami pengurangan sebanyak $67 \%$ iaitu bermula daripada hari pertama rawatan sehingga hari terakhir rawatan fitoremediasi dijalankan. Bagi sampel air yang menggunakan Pistia stratiotes, bacaan $\mathrm{NH}_{3}{ }^{-} \mathrm{N}$ menurun kepada $2.75 \mathrm{mg} / \mathrm{L}$ pada hari terakhir rawatan menunjukkan tumbuhan ini berjaya menyingkirkan $\mathrm{NH}_{3}{ }^{-} \mathrm{N}$ sebanyak $78 \%$.

Pengurangan nilai bacaan $\mathrm{NH}_{3}{ }^{-} \mathrm{N}$ menggunakan $20 \mathrm{~g}$ tumbuhan fitoremediasi ditunjukkan di dalam Rajah 7. Bacaan awal $\mathrm{NH}_{3}-\mathrm{N}$ bagi rawatan fitoremediasi menggunakan Salvinia molesta ialah $6.45 \mathrm{mg} / \mathrm{L}$ dan menunjukkan pengurangan sebanyak $96 \%$ pada hari terakhir rawatan iaitu menjadi $0.25 \mathrm{mg} / \mathrm{L}$. Bacaan awal $\mathrm{NH}_{3}{ }^{-} \mathrm{N}$ bagi rawatan fitoremediasi menggunakan Pistia stratiotes pula ialah $7.1 \mathrm{mg} / \mathrm{L}$ dan menurun pada hari terakhir rawatan dengan bacaan $1.25 \mathrm{mg} / \mathrm{L}$, menunjukkan pengurangan sebanyak $83 \%$. Kadar pengurangan kandungan $\mathrm{NH}_{3}{ }^{-} \mathrm{N}$ menggunakan $30 \mathrm{~g}$ tumbuhan fitoremediasi ditunjukkan di dalam Rajah 8. Kandungan $\mathrm{NH}_{3}{ }^{-} \mathrm{N}$ bagi rawatan fitoremediasi Salvinia molesta mengalami pengurangan sebanyak $94 \%$.

Bagi memantau kadar pengambilan ammonia dalam air kumbahan oleh Salvinia molesta, air sampel diuji setiap hari selama 8 hari rawatan. Analisis ANOVA sehala pula menunjukkan perbezaan bererti $(p<0.05)$ bagi

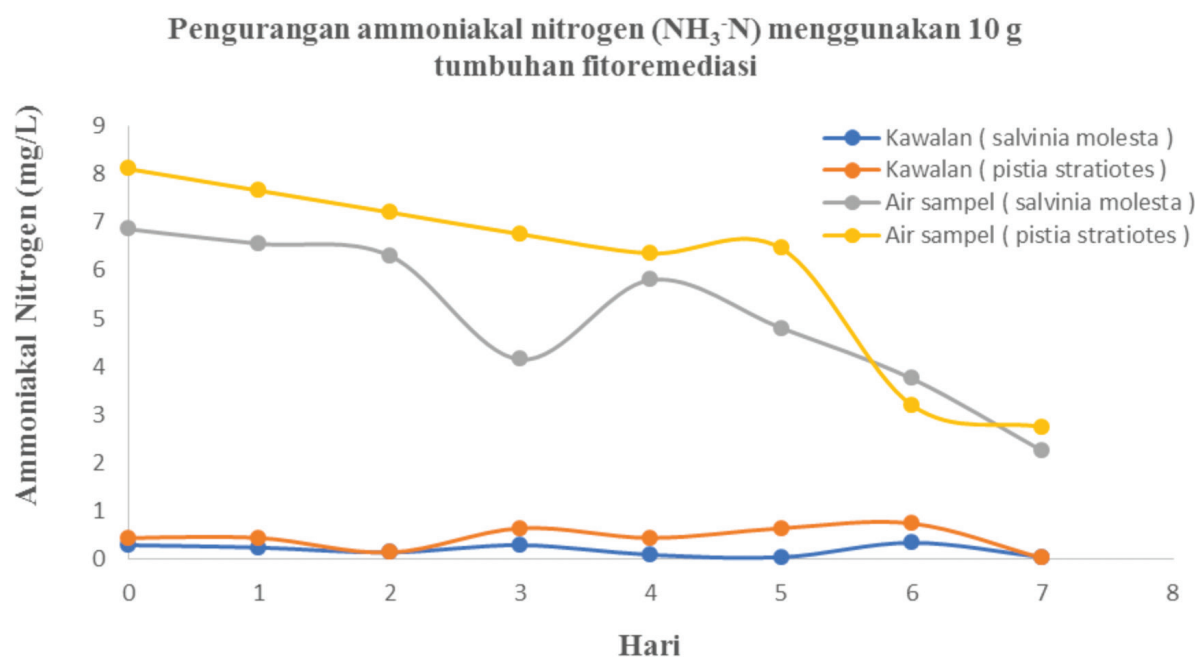

RAJAH 6. Pengurangan kandungan $\mathrm{NH}_{3}-\mathrm{N}$ menggunakan $10 \mathrm{~g}$ tumbuhan fitoremediasi

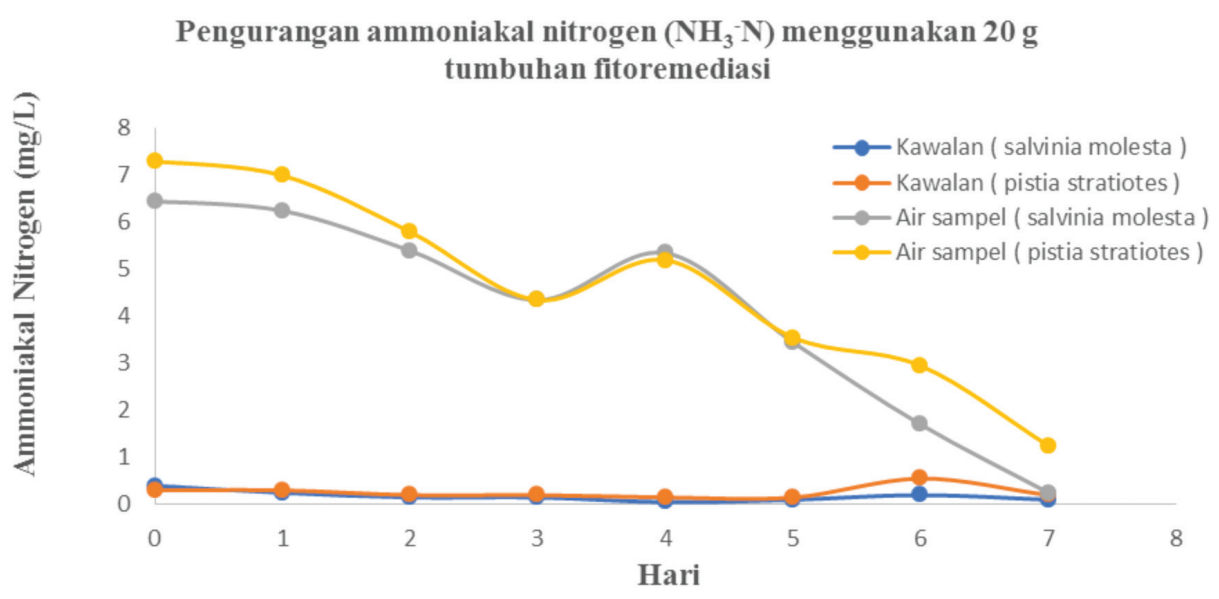

RAJAH 7. Pengurangan kandungan $\mathrm{NH}_{3}{ }^{-} \mathrm{N}$ menggunakan 20 g tumbuhan fitoremediasi 
Pengurangan ammoniakal nitrogen $\left(\mathrm{NH}_{3}{ }^{-} \mathrm{N}\right)$ menggunakan $30 \mathrm{~g}$ tumbuhan fitoremediasi

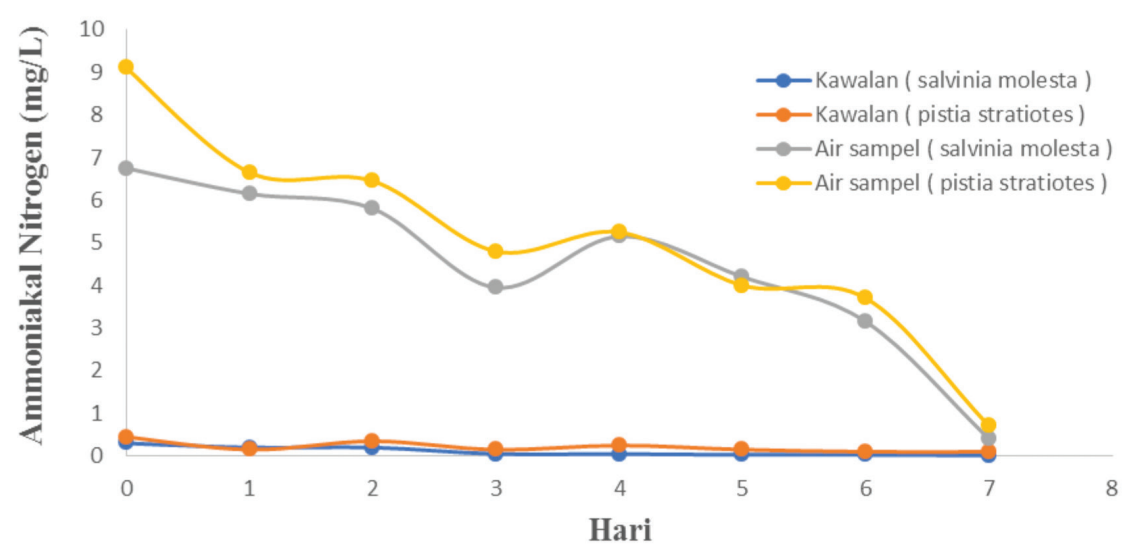

RAJAH 8. Pengurangan kandungan $\mathrm{NH}_{3}-\mathrm{N}$ menggunakan $30 \mathrm{~g}$ tumbuhan fitoremediasi

kadar pengurangan ammoniakal nitrogen di dalam plot fitoremediasi daripada hari 0 sehingga hari ke 7 . Pada permulaan rawatan fitoremediasi dijalankan, bacaan ammonia adalah tinggi disebabkan oleh penguraian bahan pepejal organik melalui tindak balas bakteria yang sedia ada di dalam air kumbahan tersebut (Ng \& Chan 2016). Selain itu juga, menurut Chavan dan Dhulap (2012), Salvinia molesta mampu menyerap nutrien dengan baik pada peringkat tumbesaran. Hal ini menunjukkan bahawa pemilihan tumbuhan juga amat penting. Oleh sebab itu, Salvinia molesta tersebut perlu dibiarkan di dalam plot yang berisi air paip untuk tujuan kultivasi $(\mathrm{Ng} \&$ Chan 2016).

Ammonia merupakan salah satu nutrien yang diperlukan oleh tumbuhan makrofit untuk membolehkan tumbuhan tersebut kekal hidup (Odjegba \& Fasidi 2004). Ini boleh dilihat sepanjang rawatan fitoremediasi ini dijalankan yang menunjukkan fluktuasi bagi graf bacaan pengurangan ammoniakal nitrogen dengan bacaan tertinggi adalah sebelum rawatan seterusnya bacaan terus menurun pada hari berikutnya sehingga berlaku sedikit peningkatan. Hal ini kerana kajian tersebut mendapat gangguan daripada segi pencahayaan pada hari tersebut. Setelah permasalahan itu diatasi, bacaan $\mathrm{NH}_{3}-\mathrm{N}$ kembali menurun sehingga hari terakhir rawatan. Berdasarkan analisis ANOVA sehala yang dijalankan, kadar pengurangan bagi bacaan $\mathrm{NH}_{3}-\mathrm{N}$ mempunyai perbezaan yang signifikan iaitu $p<0.05$. Menurut kajian Khan et al. (2014), Pistia stratiotes mempunyai kadar pengambilan nutrien yang tinggi di dalam medium yang mempunyai kepekatan nutrien sederhana.

\section{JUMLAH PEPEJAL TERAMPAI}

Pengurangan kandungan jumlah pepejal terampai (TSS) menggunakan $10 \mathrm{~g}$ tumbuhan fitoremediasi ditunjukkan di dalam Rajah 9. Bacaan awal kandungan TSS bagi tumbuhan fitoremediasi Salvinia molesta dan Pistia stratiotes, masing-masing ialah 32 dan $21 \mathrm{mg} / \mathrm{L}$. Kandungan TSS pada hari terakhir rawatan fitoremediasi Salvinia molesta ialah $9 \mathrm{mg} / \mathrm{L}$ iaitu pengurangan sebanyak 85\%. Bagi rawatan fitoremediasi Pistia stratiotes pula, pengurangan kandungan TSS ialah sebanyak $89 \%$. Rajah 10 menunjukkan kadar pengurangan nilai bacaan TSS

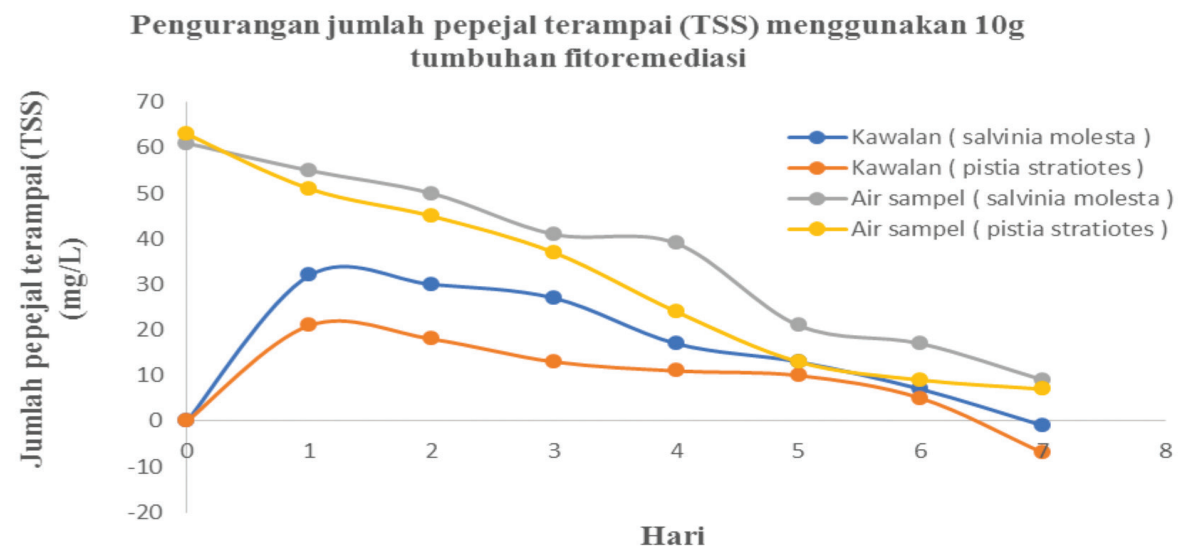

RAJAH 9. Pengurangan nilai bacaan TSS menggunakan $10 \mathrm{~g}$ tumbuhan fitoremediasi 
menggunakan $20 \mathrm{~g}$ tumbuhan fitoremediasi. Sepanjang tempoh rawatan, berlaku pengurangan kandungan TSS bagi rawatan menggunakan Salvinia molesta dan Pistia stratiotes iaitu masing-masing $88 \%$ dan $92 \%$. Berdasarkan Rajah 11, rawatan fitoremediasi sampel air kumbahan yang diletakkan tumbuhan Salvinia molesta dan Pistia stratiotes mengalami pengurangan kandungan TSS masing-masing sebanyak $87 \%$ dan $95 \%$.

Salvinia molesta mampu menjerap sehingga $96 \%$ TSS di dalam air sisa perindustrian (Ng \& Chan 2016). Ini dibuktikan lagi dengan kajian yang dijalankan dengan 20 g Salvinia molesta mampu menyingkirkan sehingga $88 \%$ TSS yang terdapat di dalam medium pada hari terakhir rawatan. Nilai peratusan dalam kajian ini sedikit berkurang berbanding kajian lepas kerana Salvinia molesta mempunyai toleransi yang tinggi di dalam medium yang mempunyai nutrien yang tinggi (Lu \& Zhenli 2010). Analisis ANOVA sehala menunjukkan perbezaan bererti $(p<0.05)$ bagi kadar pengurangan TSS daripada hari pertama rawatan sehingga hari terakhir rawatan fitoremediasi.

Berdasarkan kajian oleh Farnese et al. (2014), Pistia stratiotes mampu mengurangkan kadar TSS sehingga mencapai pengurangan $98 \%$ di dalam air sisa. Melalui kajian ini, kadar pengurangan TSS mencapai $95 \%$ bagi 30 g Pistia stratiotes. Analisis ANOVA sehala menunjukkan wujudnya perbezaan yang bererti $(p<0.05)$ bagi ketigatiga berat yang dilakukan pemantauaan selama lapan hari rawatan. Menurut Warrier (2012), akar bagi tumbuhan makrofit yang sesuai digunakan sebagai tumbuhan fitoremediasi mempunyai cas-cas yang mampu menjerap partikel serta bahan terampai yang terdapat di dalam sesuatu medium.

Rawatan fitoremediasi bagi air kumbahan menggunakan Pistia stratiotes dan Salvinia molesta tidak menunjukkan perbezaan min kadar pengurangan bagi TSS dan $\mathrm{NH}_{3}{ }^{-} \mathrm{N}$ yang signifikan antara satu sama lain. Ini dapat dibuktikan melalui analisis ANOVA sehala yang dijalankan untuk melihat perbezaan bagi pengurangan setiap parameter yang diuji bagi kedua-dua tumbuhan fitoremediasi tersebut menunjukkan nilai signifikan min adalah melebihi 0.05 bagi semua parameter. Namun begitu, tahap keberkesanan pengurangan TSS dan $\mathrm{NH}_{3}{ }^{-} \mathrm{N}$ boleh dilihat melalui nilai min yang lebih besar bagi setiap parameter yang diuji.

Pengurangan $\mathrm{NH}_{3}-\mathrm{N}$ di dalam sampel air menggunakan Pistia stratiotes lebih berkesan pada berat 10 dan 30 g berbanding dengan menggunakan Salvinia molesta. Namun begitu, nilai min pengurangan $\mathrm{NH}_{3}{ }^{-} \mathrm{N}$ bagi $20 \mathrm{~g}$ Salvinia molesta adalah lebih tinggi berbanding Pistia stratiotes. Berdasarkan kajian Rahman dan Hasegawa (2011), Pistia stratiotes mempunyai kebolehan yang lebih berkesan dalam menyingkirkan nutrien (ammonia, nitrat, fosfat dan sulfat), jumlah pepejal terampai dan logam berat di dalam air sisa perindustrian berbanding Salvinia molesta .

Bagi pengurangan kandungan TSS di dalam air sampel adalah lebih berkesan dengan menggunakan Pistia stratiotes berbanding Salvinia molesta. Tahap keberkesanan rawatan Pistia stratiotes dapat dibuktikan melalui nilai min pengurangan TSS dengan menggunakan 10 dan 20 g Pistia stratiotes. Namun begitu, bagi $30 \mathrm{~g}$ Pistia stratiotes, nilai min pengurangan TSS lebih rendah berbanding Salvinia molesta. Menurut Warrier dan Saroja (2002), Pistia stratiotes berkesan dalam memerangkap TSS kerana struktur akarnya yang lebih besar dan mempunyai lebih banyak rerambut berbanding Salvinia molesta.

Air yang dirawat melalui proses fitoremediasi ini boleh digunakan semula untuk tujuan irigasi pertanian, kegunaan domestik ataupun dilepaskan semula ke badan air. Pelbagai pihak terutamanya sektor perindustrian menggunakan semula air sisa yang telah dirawat untuk pelbagai tujuan lain. Oleh itu, kualiti air yang dirawat perlu mengikut piawaian Indeks Kualiti Air (WQI) yang telah ditetapkan oleh Jabatan Alam Sekitar selain perlu dibandingkan dengan Piawaian Kualiti Air Kebangsaan Malaysia (NWQS) yang telah digubal oleh Jabatan Alam Sekitar, Malaysia.

Pengurangan jumlah pepejal terampai (TSS) menggunakan $20 \mathrm{~g}$ tumbuhan fitoremediasi

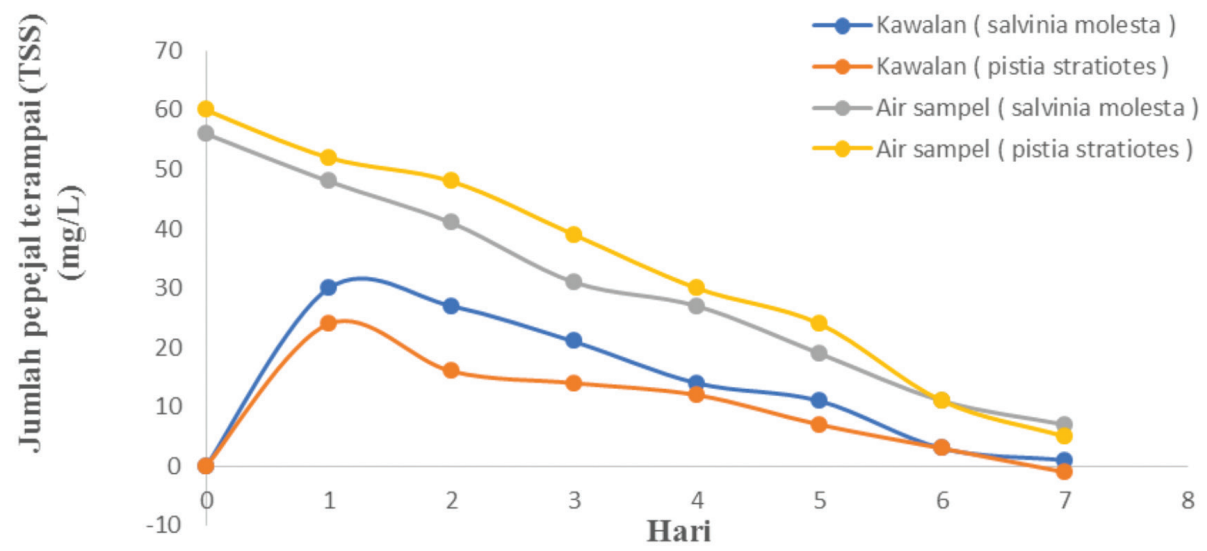

RAJAH 10. Pengurangan kandungan TSS menggunakan $20 \mathrm{~g}$ tumbuhan fitoremediasi 
Pengurangan jumlah pepejal terampai (TSS) menggunakan $30 \mathrm{~g}$ tumbuhan fitoremediasi

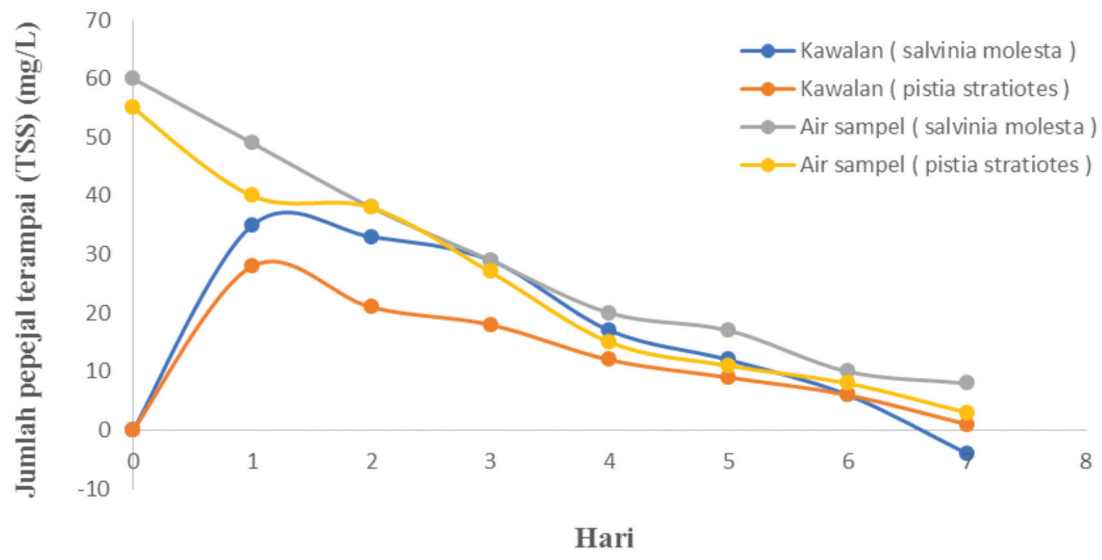

RAJAH 11.Pengurangan kandungan TSS menggunakan $30 \mathrm{~g}$ tumbuhan fitoremediasi

\section{KESIMPULAN}

Kajian ini bertujuan untuk melihat tahap keberkesanan Salvinia molesta dan Pistia stratiotes sebagai tumbuhan fitoremediasi dalam air sisa kumbahan dari loji kumbahan UKM Bangi. Pengurangan jumlah pepejal terampai dan ammoniakal nitrogen di dalam air sisa kumbahan oleh Salvinia molesta dan Pistia stratiotes dibandingkan dengan tiga berat tumbuhan yang berbeza $(10,20$ dan $30 \mathrm{~g}$ ). Melalui kajian ini, $30 \mathrm{~g}$ Pistia stratiotes berkesan dalam menyingkirkan jumlah pepejal terampai sehingga mencapai $95 \%$ dan juga $92 \%$ penyingkiran ammoniakal nitrogen pada hari terakhir rawatan, manakala $10 \mathrm{~g}$ Pistia stratiotes berjaya mengurangkan $78 \%$ ammoniakal nitrogen dan $89 \%$ jumlah pepejal terampai. $20 \mathrm{~g}$ Salvinia molesta pula berjaya mengurangkan sebanyak $96 \%$ kandungan ammoniakal nitrogen dan $88 \%$ jumlah pepejal terampai di dalam air sisa kumbahan. Kesimpulannya, rawatan fitoremediasi merupakan salah satu alternatif berkos rendah dan mesra alam dalam rawatan air sisa. Namun, pemilihan tumbuhan yang tepat juga penting bagi memastikan keberkesanan rawatan fitoremediasi tersebut. Penuaian secara berkala perlu dilakukan apabila tumbuhan tersebut mereput untuk mengelakkan nutrien dilepaskan semula ke dalam jasad air. Oleh itu, jasad air perlu dipelihara untuk mengelakkan berlakunya pencemaran yang memerlukan rawatan air.

\section{PENGHARGAAN}

Penghargaan diberikan kepada geran (ST-2016-015) dan (FRGS/2/2013/STWN01/UKM/03/1) yang telah membiayai projek ini.

\section{RUJUKAN}

Azahan, A., Jamaluddin, M.J. \& Suhaily, M. 2001. Status dan pengurusan kualiti air Sungai Linggi. Dlm Environmental Management. Proceeding National Seminar on Environmental Management: Current Development \& Future Planning.
Baharim, N.B., Yusop, Z., Yusoff, I., Tahir, W., Askari, M., Othman,Z.\& Abidin, M.R.Z. 2016. The relationship between heavy metals and trophic properties in Sembrong Lake, Johor. Sains Malaysiana 45(1): 43-53.

Bakar, A.F.A., Barkawi, S.N.M., Hanafiah, M.M., Lee, K.E. \& Halim, A.A. 2016. Penyingkiran ammonia dan logam berat daripada air sisa industri automotif menggunakan pasir terubah suai secara kimia. Sains Malaysiana 45(10): 1509-1516.

Chavan, B.L. \& Dhulap, V.P. 2012. Treatment of sewage through phytotechnical studies with constructed wetland using Eichhornia crassipes. Journal of Environmental Research and Development 7(2): 660-666.

Din, H.M., Toriman, M.E., Mazlin, M., Rahmah, E.,Aziz, N.A.A., Abdullah, N.M. \& Kamarudin, M.K.A. 2012. Kepekatan beban bahan pencemar di alur ilmu kampus UKM Bangi: Kaedah min kepekatan peristiwa (Emc). The Malaysian Journal of Analytical Sciences 16(3): 353-365.

Dixit, A., Dixit, S. \& Goswami, C. 2011. Process and plants for wastewater remediation: A review. Scientific Reviews and Chemical Communications 1(1): 71-77.

Elias, S.H., Mohamed, M., Nor-Anuar, A., Muda, K., Hassan, M., Othman, M. \& Chelliapan, S. 2014. Water hyacinth bioremediation for ceramic industry wastewater treatment Application of rhizofiltration system. Sains Malaysiana 43(9): 1397-1403.

Farnese, F.S., Oliveira, J.A., Lima, F.S., Leao, G.A., Gusman G.S. \& Silva, L.C. 2014. Evaluation of the potential of Pistia stratiotes L. (water lettuce) for bioindication and phytoremediation of aquatic environments contaminated with arsenic. Brazilian Journal of Biology 74(3): 103-112.

Gasim, M.B., Zakaria, N., Umar, R. \& Mustafa, A.D. 2012. Analisis kualiti air fiziko-kimia dan kandungan mikrob di Hulu Sungai Langat, Selangor. Malaysian Journal of Analytical Sciences 19(5): 1072-1083.

Halim, A.A., Hanafiah, M.M. \& Khairi, A. 2017. Ammonia removal from sewage wastewater using chemically modified sand. Applied Ecology and Environmental Research 15(3): 521-528.

Halim, A.A., Han, K.K. \& Hanafiah, M.M. 2015. Removal of methylene blue from dye wastewater using river sand by adsorption. Nature Environment and Pollution Technology 14(1): 89-94. 
Khan, M.A., Marwat, K.B., Gul, B., Wahid, F., Khan, H. \& Hashim, S. 2014. Pistia stratiotes L. (Araceae): Phytochemistry, use in medicines, phytoremediation biogas and management options. Pakistan Journal Botany 46(3): 851-860.

Lemon, G.D. \& Posluszny, U. 1997. Shoot morphology and organogenesis of the aquatic floating fern Salvinia molesta D.S. Mitchell, examined with the aid of laser scanning confocal microscopy. International Journal of Plant Sciences 158(6): 693-703.

Lu, Q. \& Zhenli, L. 2010. Phytoremediation to remove nutrients and improve eutrophic stormwaters using water lettuce (Pistia stratiotes). Environmental Science Pollution Research 17: 84-96.

Ma'arof, N. \& Hua, A.K. 2015. Kualiti air Sungai UTM: Satu penilaian awal berpandukan enam parameter indeks kualiti air. Malaysian Journal of Society and Space 11(1): 107-115.

Manan, F.A., Tsun-Thai, C., Samad, A.A. \& Mamat, D.D. 2015. Evaluation of the phytoremediation potential of two medicinal plants. Sains Malaysiana 44(4): 503-509.

Meagher, R.B. 2000. Phytoremediation of toxic elemental and organic pollutants. Current Opinion in Plant Biology 3: 153-162.

Ng, Y.S. \& Chan, D.J.C. 2016. Wastewater phytoremediation by Salvinia molesta. Journal of Water Process Engineering 15: $107-115$

Odjegba, V.J. \& Fasidi, I.O. 2004. Accumulation of trace elements by Pistia stratiotes: Implications of phytoremediation. Ecotoxicology 13: 637-646.

Rahman, M.A. \& Hasegawa, H. 2011. Aquatic arsenic: Phytoremediation using floating macrophytes. Chemosphere 83(5): 633-646.

Shuger, G.J., Bauman, S.L., Drum, D.A. \& Lauber, J. 2001. Environmental Field Testing and Analysis Ready Reference Handbook. New York: McGraw-Hill Companies, Inc.
Subramaniam, D., Halim, A.A. \& Hanafiah, M.M. 2016. Performance of electrochemical oxidation in treating textile industry wastewater by graphite electrode. Nature Environment and Pollution Technology 15(3): 1021-1026.

Suhaimi, A.A. \& Samah, M.A.A. 2013. Fitopemulihan merawat air kumbahan. Dewan Kosmik.

Suratman, A., Suhaimi, A. \& Lo, T.T. 2005. Penilaian indeks kualiti air di Lembangan Sungai Ibai, Terengganu. Sains Malaysiana 34(2): 55-59.

Warrier, R.R. 2012. Phytoremediation for environmental clean up. Forestry Bulletin 12(2): 1-7.

Warrier, R.R. \& Saroja, S. 2002. Phytoremediation: A remedy to environmental problems in urban areas. Indian Journal of Environmental Protection 22(2): 225-228.

Pusat Pengajian Sains Sekitaran dan Sumber Alam

Fakulti Sains dan Teknologi

Universiti Kebangsaan Malaysia

43600 UKM Bangi, Selangor Darul Ehsan

Malaysia

*Pengarang untuk surat-menyurat; email:mhmarlia@ukm.edu. my

Diserahkan: 14 September 2017

Diterima: 17 Mac 2018 